\title{
Reformation Methods of Physical Education Teaching in Higher Vocational Colleges from the Perspective of New Media
}

\author{
Chungang Yi \\ Jiangxi Technical College of Manufacturing 330095, China
}

Keywords: Physical Education teaching in Higher Vocational Colleges; new media; teaching; reformation

\begin{abstract}
The development of new media has brought huge influences on Physical Education (PE) teaching in Higher Vocational Colleges. The physical teaching in the mentioned colleges should make full use of new media to enhance teaching efficiency. This paper firstly analyzes the current status of PE teaching in Higher Vocational Colleges, then explores the influence of new media on teaching effects, and lastly, proposes several reformation methods of PE teaching in higher vocational colleges from the perspective of new media.

In the mobile Internet era, new media is experiencing a rapid development and becomes more and more popular in various fields. In the view of PE teaching in Higher Vocational Colleges, under the new media environment, in addition to the constantly updated teaching environment as well as students' continuously changing learning needs, shortages of traditional PE teaching modes in Higher Vocational Colleges have become increasingly prominent. Topics that how to give a full play to the advantages and functions of new media, then promote the reformation and innovation of $\mathrm{PE}$ teaching in Higher Vocational Colleges are quite worth exploring.
\end{abstract}

\section{Analysis of Current Status of PE Teaching in Higher Vocational Colleges}

PE teaching in Higher Vocational Colleges takes the mode of elective course with the purpose of cultivating students' competence to get familiar with sports skills and develop lifelong physical consciousness. However, from the perspective of current status, in some colleges, their teaching deviates from the original goals. Moreover, the teaching fails to keep up with social needs, not mention to cultivate students' interests in sports, sports habits and lifelong sports consciousness. Higher vocational education is employment oriented, therefore, courses to develop qualities like PE classes hadn't receive sufficient attention. There is not a reasonable planning system for PE courses and teachers just follow the prescribed requirements to consume physical classes. Some higher vocational students also agree that PE classes are not indispensable and not worth extra time to do sports training. In actual teaching, within an academic year, PE classes are quite vulnerable to varying factors like weather, students' practical training and so on. Students' physical learning time of some majors fails to meet the teaching plan and syllabus requirements. ${ }^{\text {[1] }}$

Secondly, from the term of teaching contents, many Higher Vocational Colleges arrange PE public basic course only in the first year, then cancel it in the second year. Teaching contents are basically some sports items like basketball, football, volleyball and so on. In addition, PE classes are comparatively fewer and teaching time is shorter than other courses. Usually, in PE classes, students are in a large number which makes teaching contents hard to go deep. This kind of monologue teaching contents can not stimulate students' interests and enthusiasm for sports learning and fail to meet their sports learning needs. During teaching, some teachers only allow students to do independent activities, thus teaching is merely a formality and could not offer professional sports guidance for students.

From the view of teaching methods, the most frequently used one is teachers' teaching and students' imitation. The later depends on the former greatly and losing their independence. As for 
the teaching mode, it usually adopts decomposition teaching, demonstration and so on. In this kind of teaching practice, teachers always stress the explanation of teaching contents which is quite boring and lacking guiding characteristics. It is difficult for students to combine learning knowledge with physical exercises in daily life although lots of higher vocational students have insufficient sports. Moreover, many colleges do not take physical teaching seriously. PE classes are reduced largely and many students are not willing to take PE classes. Due to a lack of attention to physical teaching and limited management investment, PE teaching confronts restriction. Furthermore, extra-curriculum sport activities are short of innovation and fail to lead students to participate in various social physical activities.

Overall, for PE teaching in Higher Vocational Colleges, there are still a lot of problems existing in teaching objectives, teaching contents and modes etc. With the development of modern education system as well as students' new physical learning needs, higher vocational teaching worth our most urgent attention. As a product of Internet era, new media creates many advantages for the development of PE teaching in Higher Vocational Colleges. Now, much urgent attention have been attached to questions like how to actively use new media to promote the reformation of PE teaching in Higher Vocational Colleges and then improve its teaching quality.

\section{Influence of New Media on PE Teaching in Higher Vocational Colleges}

New media is featured with real-time, interaction and sharing quality etc. At present, Internet with new media has become the main channel for college students to receive information and the important tools in their life as well as learning. Based on the perspective of new media, it has promoted teaching reformation from teaching resources, teaching methods and teaching management. Specifically, new media has brought teaching materials reformation which turns paper materials to electronic materials. It has also changed learning methods that turns the traditional classroom learning to spaced learning. It enables students to study at any time or any where through smart mobile terminals such as intelligent phones and tablet computers. For Higher Vocational Colleges, under new media environment, PE teaching reformation also has ushered new development. It enriches teaching contents. Besides, based on new media's abundant information, real-time and interactive characteristics, students are allowed to contact more sports items which can expand their sport sights and activate sports participation interests. ${ }^{\text {[2] }}$ The rich contents of new media satisfy students' learning needs. So far, PE teaching contents in Higher Vocational Colleges can not meet students' exercising needs while new media is able to provide numerous resources for them to study autonomously. It allows students to choose sports items according to their own conditions and interests on Internet, then do autonomous learning by new media resources. Through reasonable exercising arrangement, students will achieve progress in interested fields, then realize personalized development. Moreover, based on new media platform of Internet, PE teaching in Higher Vocational Colleges is able to change efficiently the current one-way teaching mode and improve students' activity. New media platforms such as WeChat can realize the communication and cooperation between teachers and students as well as Internet learning. By new media, students will get rid of excessive dependence on sports classroom and teachers. Through Internet research and application of new media teaching modes like Micro Class and Mooc, students are enabled to study at any time and observe repeatedly which will enhance learning efficiency comprehensively. Moreover, new media is capable of improving teaching quality. PE can not carried out without dynamic demonstration teaching. In traditional physical teaching, students usually can not master some difficult actions just from teachers' simple demonstration. However, by new media platform of Internet, it is feasible to show dynamically various sports information, skills and so on which is more conducive for practical teaching.

At the same time, new media also has brought some negative effects on PE teaching in Higher Vocational Colleges. Specifically, the application of new media in the practice of PE teaching weakens the authenticity of PE to some extent. In traditional classes, by face to face communication, teachers are capable of adjusting teaching contents and methods in accordance of practical situations. Although new media is more convenient and efficient, it can not make students all-round 
experience and weakens the feeling of participation. Besides, the usage of new media also affects the scientific formation of students' sports skills to certain degree. In traditional teaching, teachers carry out teaching activities step by step according to regular exercise programs, enabling the formation of scientific sport habits. While by new media, it is hard for students to accurately control learning outcomes. Moreover, in new media, the resources are so abundant that some non-authoritative and non-official sports teaching resources will quite easily result into incorrect physical exercise habits or even influence body health. Therefore, PE reformation in Higher Vocational Colleges should not only make full use of the characteristics and advantages of new media, but also take into account the adverse effects of new media. ${ }^{\text {[3] }}$

\section{Reformation Strategies of PE Teaching in Higher Vocational Colleges Based on New Media}

PE teaching managers in Higher Vocational Colleges are required to enhance their understanding and strengthen attention to PE teaching. They need to know the effects of new media on the environment and modes of higher vocational teaching. There are some specific methods stipulated. To combine the features of professional talent cultivation mechanism, to plan systematically for the reformation of PE teaching, coordinate scientifically the Internet teaching system and perfect application mechanism of new media teaching curriculum. Define requirements for Internet teaching, Internet course selection, physical teaching assessment and teaching quality etc to promote the formation of systematic specification. Teachers are also required to enhance objective understanding of new media, master its characteristics, constantly sum up the bounding point between new media and teaching practice, promote understanding and grasp teaching skills of new media. Simultaneously, it is suggested for Higher Vocational Colleges to strengthen related training of new media application, lead teachers to improve their new media teaching application skills and make knowledge processing as well as teaching design ability sound.

It is feasible for PE teachers to effectively integrate all kinds of scientific and excellent Internet teaching resources or make short videos independently. Teachers are recommended to put Internet teaching on new media platforms such as WeChat, and achieve a combination of online and offline sports teaching which forms the online teaching based on classroom teaching. For example, as for aerobics, the learning of yoga and some other programs, teachers are able to upload related videos or slides to online platforms such as WeChat groups and public platforms. Then, in combination with new media, teachers can lead students to regulate their own actions, cultivate sense of beauty and gradually establish sports learning interests and confidence. Simultaneously, apart from program selection, PE teachers can set up PE selective courses by effective combination with students' major features. In this way, teachers are capable of producing micro videos with major characteristics which adapt to students' major development needs and satisfy their interests. These micro videos allow students to choose learning contents by themselves. ${ }^{[4]}$

In teaching practices, teachers should actively make use of new media and reform teaching methods, cultivating students' learning interests and independent sports habits. For example, it is advised to establish a PE WeChat public platform, then renovate regularly sports news and related information, providing more interesting contents and allowing students to learn in spare time. In addition, it is supposed to take advantage of new media to lead students to do extra-curriculum physical exercise since a class of teaching can not improve efficiently their physical quality, not mention students' physical exercise habits. While it is quite necessary to cultivate students' extra-curriculum physical exercise habits. Teachers are advised to make full use of new media to lead students to strengthen exercises. For instance, the popular sports pedometer software can be used to require students to complete a certain number of steps per day. The step counting software's sports recording will be taken as the homework assessment, by which students are encouraged to develop physical exercise habits. ${ }^{[5]}$ Furthermore, it is also proposed to use new media to enhance the propaganda of sports culture, enhance students' participation and motivation in sports and develop their sports consciousness. For example, WeChat, Micro-blog and broadcast can be applied to report activities of sports associations and sports meetings, create a good sports atmosphere and form a subtle influence on students. 
Higher Vocational Colleges should strengthen the management and supervision of new media teaching work, effectively avoid the negative factors and promote its active role in sports teaching. To be specific, in Higher Vocational Colleges, systematic supervision mechanism for new media information needs to be built to strictly supervise and manage Internet information source and broadcasting channels, ensure that all students receive positive and scientific sports information and then remove negative contents. At the same time, Higher Vocational Colleges need to continuously explore the bonding point between new media and physical education teaching, master actively the development trend and latest trends of new media and make full use of its advantages. Teachers are supposed to combine efficiently the features of PE teaching with the characteristics of higher vocational students, and constantly optimize as well as correct teaching in accordance with students' experience and feedback.

\section{Conclusion}

In a word, with its immediacy, interactivity and mass quality, new media has brought great changes as well as challenges to PE teaching in Higher Vocational Colleges. Teachers should actively make full use of new media, define teaching objectives, enrich teaching methods, promote teaching efficiency and stimulate the realization of PE teaching objectives in combination with students' learning needs and habits.

\section{References}

[1]Dong Hongyin. An Exploration of Internet Media Application in Physical Education Teaching in Higher Vocational Colleges [J]. Journal of the Staff and Worker's University, 2015 (3): 105-107.

[2]Gong Wei. Construction of WeChat Public Platform for Physical Education Teaching in Higher Vocational Colleges [J]. Journal of Jilin Teachers Institute of Engineering an Technology, 2017(3): 27-30.

[3]Dong Lihua. A Study of New Media’s Influence on Higher Vocational Students' Learning [J]. Science \& Technology Information, 2016 (3): 112-113.

[4]Jin Yunyan. Construction of Internet Autonomous Learning Platform for Physical Education Teaching in Higher Vocational Colleges under New Media Environment [J]. Sports, 2017 (8): 127-129.

[5]Yan Xiaohui. How to Strengthen the Application of New Media in Physical Education Teaching in Higher Vocational Colleges [J]. Selected Works of Young Writers, 2015 (4): 183-184. 